Research Article

\title{
Cement Slurry Plugging Law and Optimal Plugging Flow Rate at a High Hydraulic Gradient
}

\author{
Peili Su, ${ }^{1,2}$ Yifei Jia $\mathbb{D}^{2}{ }^{2}$ Feng Liu, ${ }^{2}$ and Chong $\mathrm{Li}^{2}$ \\ ${ }^{1}$ Xi'an Key Laboratory of Geotechnical and Underground Engineering, Xi'an University of Science and Technology, \\ Xi'an 710061, China \\ ${ }^{2}$ School of Architecture and Civil Engineering, Xi'an University of Science and Technology, Xi'an 710061, China \\ Correspondence should be addressed to Yifei Jia; 18204209070@stu.xust.edu.cn
}

Received 9 December 2020; Revised 14 March 2021; Accepted 18 May 2021; Published 25 May 2021

Academic Editor: Sadik O. Degertekin

Copyright (c) 2021 Peili Su et al. This is an open access article distributed under the Creative Commons Attribution License, which permits unrestricted use, distribution, and reproduction in any medium, provided the original work is properly cited.

\begin{abstract}
With the continuous development of coal and rock mass engineering, water inrush grouting has become an urgent problem in engineering disaster management. Herein, a theoretical model of the optimal plugging flow rate was established, and a comparative theoretical analysis was performed based on the results of indoor model tests. The particle incipient velocity was defined as the optimal plugging flow rate. The effects of hydrodynamic velocity, water-cement ratio, grouting pressure, and fracture aperture on the cement slurry grouting plugging were studied, and the optimal threshold of the plugging flow rate was obtained for theoretical model verification. Results showed that, at a high hydraulic gradient, the plugging effect of the grout was mainly affected by the hydrodynamic velocity, water-cement ratio, and grouting pressure (listed in the order of importance). When the hydrodynamic velocity was low, the difference in the slurry deposition thickness was large under different water-cement ratios and pipe diameters. When the hydrodynamic velocity was increased, the influence of various factors on the slurry deposition thickness decreased. Through a comparative analysis of the experimental and theoretical values, the optimal plugging velocity of pure cement slurry was $0.5-0.55 \mathrm{~m} \cdot \mathrm{s}^{-1}$ under different conditions, and the error between the experimental and theoretical values was less than $0.1 \mathrm{~m} \cdot \mathrm{s}^{-1}$, which confirmed the rationality of the proposed model.
\end{abstract}

\section{Introduction}

Under western developmental strategies, the numbers of urban subways, deep mines, cross-sea tunnels, and other projects have increased in China. The developers of coal and rock mass projects encounter complex geological structures, variable environments, and frequent disasters [1-5]. Water inrush disasters are the most frequent and damaging events in coal and rock mass engineering, accounting for more than half the total number of accidents occurring in this field [6-8]. Grouting is the main protective measure against water inrush disasters; however, traditional grouting approaches are ineffective against water inrush disasters with large flows and high hydrodynamic velocities. Under such conditions, the grout retention rate is extremely low. Intercepting the water passage will decelerate the flow, and grouting is performed to improve the blocking effect. However, when the flow-drop rate is small, the hydrodynamic velocity remains high, the slurry retention rate remains low, and the grouting effect remains poor. Conversely, when the flowdrop rate is large, the hydrodynamic velocity is significantly reduced; however, the excessive amount of materials causes slurry sedimentation. By studying the grouting plugging law of cement slurry under high-hydraulic-gradient conditions, we can provide guidance for disaster prevention and mitigation in grouting water plugging engineering.

To this end, many researchers have investigated grouting plugging against large flow rates of dynamic water. Using theoretical analyses and laboratory experiments, Li et al. [9] studied the flow control and grouting blocking mechanism of gushing karst pipeline water with large flows and proposed a complete set of treatment methods under this condition. Niu [10] established a three-dimensional fracture model of large-flow and high-hydraulic-gradient 
groundwater using a fluent numerical simulation software. Based on the time-varying viscosity of the slurry, the author deduced the migration law and diffusion of the slurry in a fracture channel and the changes in the pressure and velocity fields. Li et al. [11] characterized the time-varying characteristics of slurry viscosity using the Sequential Diffusion and Solidification (SDS) method and verified the simulation results in laboratory tests of pipeline-type dynamic water grouting. In SDS simulations of grout plugging in large-flow and high-hydraulic-gradient moving water, the mechanism of flow control and speed reduction using dual-hole-combined grouting was revealed, providing a theoretical basis for engineering projects [11]. Liu and Huang [12, 13] numerically simulated the erosion-resisting characteristics of a new cement paste. Using the Bingham model, they controlled the grouting and water flow rates and studied the antiscouring ability of the paste. Zhang et al. [14] experimentally investigated porous aggregate infusions in a mine submerged beneath a roadway. By combining the results of an indoor experiment with theory, they established a visual pipelineaggregate infusion test platform for analyzing the hydrodynamic velocity and the influence of different factors on aggregate plugging. Aggregate interception and water shutoff were mainly affected by the hydrodynamic velocity and aggregate particle sizes. From these results, Zhang et al. [14] derived the law of aggregate sedimentary migration and accumulation. Li et al. [15] developed a grouting-model test bed that visualizes fracture developments under a dynamic water supply. They examined water inrush through a fractured rock mass, clarified the layered and partitioned diffusion mechanism of cement slurry, and obtained a U-shaped diffusion of the slurry and the sectionalized and layered diffusion mechanism of grout. Chang [16] established a multipipe water-gushing flow model and analyzed the mutual influence of the slurry type and pipeline on the grouting of multiple pipes. Combining numerical simulations and laboratory experiments, Chang [16] proposed a grouting treatment method that "controlled the flow rate at the gushing point + provided preferential treatment for branch pipelines + combined grouting and blocking for main pipelines." Zhang et al. [17] proposed a stepwise calculation method for describing the grouting process according to pressure and flow control conditions and analyzed the pressure distribution in the grouted zone using case studies. Du et al. [18] performed a series of experiments to show the sealing efficiency mechanism of cement grouting in tortuous fractures with flowing water and verified it using engineering applications. Liang et al. [19] reported a critical inclined angle $\left(12.4^{\circ}\right)$ that differentiates the grout patterns into two types, namely, the gel deposition grout pattern and erosion dispersion grout pattern. When the inclination angle was greater than the critical inclination angle, grouting could not stop the water and sand flow. Some researchers [20-23] have numerically analyzed the diffusion law of cement grout in rock mass fractures and the influences of fracture aperture and grout properties on rock mass grouting.

In summary, grouting under high hydraulic slope is quite different from the traditional fracture grouting. The retention rate of grout in this state is much lower than that of low-velocity fracture grouting; therefore, it is generally necessary to first use aggregate infusion to form a waterblocking section and then reduce the flow rate before grouting [24-26]. However, the hydrodynamic velocity, when the aggregate is poured, and optimal grouting effect (here, defined as the optimal plugging effect of the hydrodynamic velocity) have not been investigated. Additionally, current studies on grout plugging have typically focused on stagnant or low-velocity fissure water [24, 27-31]. The grouting plugging law in coal rock mass fractured owing to high-hydraulic-gradient water has not been considerably investigated. To fill this gap, in this study, an indoor test of grout plugging was performed under high-hydraulic-gradient conditions, and a theoretical model was established to explore the grouting plugging law of cement grout under different working conditions (water-cement ratio, fracture aperture, and hydrodynamic velocity). By optimizing the plugging threshold of the hydrodynamic velocity and addressing the unanswered questions in this field, we provide important guidance for elucidating the grout diffusion mechanism and targeted prevention. The presented result provides a future exploration path and will beneficially supplement the grouting plugging system under high hydraulic slopes.

\section{Materials and Methods}

2.1. Model of Optimal Plugging Flow Rate. In slurry transportation, the minimum hydrodynamic velocity at which particles leave a crack beneath the flow is called the incipient [32-38] or accumulation velocity. At the incipient velocity, particles start to move by rolling and migration. When the hydrodynamic velocity exceeds the incipient velocity, the particles cannot remain in the cracks. When the hydrodynamic velocity exceeds the starting flow rate under given conditions, grouting is an ineffective solution for cement slurry crack plugging (Figure 1). Therefore, the incipient velocity of the cement particles was used as the optimal plugging flow rate in this research.

2.1.1. Basic Hypothesis. To optimize the plugging flow rate of the cement slurry, the following assumptions were made:

(1) The water flow in the fracture is turbulent (Reynolds number $(\mathrm{Re}) \geq 4000)$

(2) The slurry comprises discrete particles at a high hydraulic gradient

(3) The slurry is in the initial injection state, and its viscosity is constant

(4) The cement particles are spherical, and their diameters are assumed to be the average particle size

2.1.2. Initiation Conditions of a Single Cement Particle. Initially, the stationary cement particles begin to move along the bottom of the fissure. They are mainly affected by the drag force $F_{D}$ of the water flow, upward force $F_{L}$ of the water flow, effective gravity $W$, and bonding force $N$ between the particles, which are, respectively, expressed as 


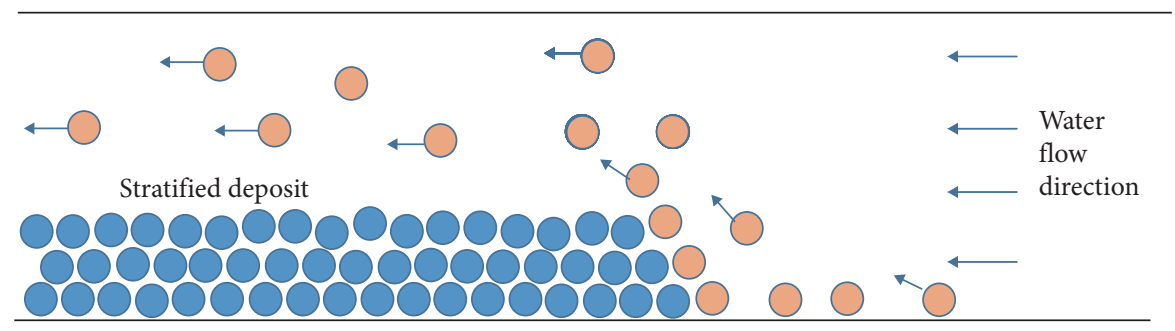

FIGURE 1: Schematic of the incipient motion of cement particles.

$$
\begin{aligned}
F_{D} & =\frac{1}{8} C_{D} \pi d_{P}^{2} \rho u^{2}, \\
F_{L} & =\frac{1}{8} C_{L} \pi d p^{2} \rho u^{2}, \\
W & =\frac{\pi}{6} d_{p}^{3}\left(\rho_{p}-\rho_{g}\right) g, \\
N & =\frac{\sqrt{3}}{4} \pi q_{0} \delta_{0}^{3} d_{P}\left(\frac{1}{t^{2}}-\frac{1}{\delta_{1}^{2}}\right)\left(3-\frac{t}{\delta_{1}}\right),
\end{aligned}
$$

where $C_{D}$ and $C_{L}$ are the coefficients of the drag and uplifting forces, respectively (here, they are set to 0.4 and 0.1 , respectively), $u$ is the instantaneous hydrodynamic velocity at the bottom of the water flow when the particles are entrained, $\rho_{p}$ and $\rho_{g}$ are the densities of cement and water, respectively, $d_{P}$ is the diameter of the cement particles, $\delta_{0}$ is the thickness of a water molecule (generally considered as $\left.3 \times 10^{-10} \mathrm{~m}\right), \quad \delta_{0}$ is the water thickness of the film $\left(4 \times 10^{-7} \mathrm{~m}\right)$ [39], $t$ is the interparticle distance (generally set to $\left.0.25 \delta_{1}\right)$, and $q_{0}$ is the binding force of the particles per unit area at $t=\delta_{0}$ (here, it is set to $1.3 \times 10^{9} \mathrm{~kg} / \mathrm{m}^{2}$ ).

By setting point $\mathrm{O}$ as the center of rotation (Figure 2 ) and $\sum M=0$, the critical equation at which the cement particles start moving is expressed as

$$
F_{D} K_{1} d+F_{L} K_{2} d=W K_{3} d+N K_{4} d,
$$

where $K_{1} d, K_{2} d, K_{3} d$, and $K_{4} d$ are the arms of (force) $F_{D}$, $F_{L}, W$, and $N$, respectively, with $K_{1}=K_{2}=K_{3}=K_{4}=1$.

Substituting equations (1)-(4) in (5), we obtain

$$
\begin{gathered}
\frac{1}{8} C_{D} \pi d_{P}^{2} \rho u_{0}^{2}+\frac{1}{8} C_{L} \pi d_{P}^{2} \rho u_{0}^{2}=\frac{\pi}{6} d_{p}^{3}\left(\rho_{p}-\rho_{g}\right) g+\frac{\sqrt{3}}{2} \pi q_{0} \delta_{0}^{3} r\left(\frac{1}{t^{2}}-\frac{1}{\delta_{1}^{2}}\right)\left(3-\frac{t}{\delta_{1}}\right), \\
u_{0}=\left[\frac{1}{\rho\left(C_{L}+C_{D}\right)}\right]^{1 / 2}\left[\frac{4 d_{p}\left(\rho_{p}-\rho_{g}\right) g}{3}+\frac{2 \sqrt{3} \pi q_{0} \delta_{0}^{3}\left(\left(1 / t^{2}\right)-\left(1 / \delta_{1}^{2}\right)\right)\left(3-\left(t / \delta_{1}\right)\right)}{\pi d_{p}}\right]^{1 / 2} . \\
\sigma_{1}=0.37 \overline{u_{1}} .
\end{gathered}
$$

The first movement of the cement particles is a random phenomenon. Whether the stationary particles start to move under a water flow depends on their position and exposure to the flow rate; consequently, no water flow condition can simultaneously initiate the moving state of all particles [28]. Therefore, as the motion-start criterion, the particle-starting probability of the cement particles is expressed as follows:

$$
\varepsilon=P\left(u_{1}^{2} \geq u_{0}^{2}\right)
$$

As the instantaneous hydrodynamic velocity $u_{1}$ at the bottom of the water flow approximately obeys a normal distribution, and the probability of sliding in the countercurrent direction is extremely small, the second term $\varnothing$ (.) of the normal distribution function can be ignored. Thus, equation (8) can be expressed as

$$
\varepsilon=1-\left(\Phi \frac{u_{0}-\overline{u_{1}}}{\sigma_{1}}-\Phi \frac{-u_{0}-\overline{u_{1}}}{\sigma_{1}}\right)=1-\Phi \frac{u_{0}-\overline{u_{1}}}{\sigma_{1}}
$$

where $\overline{u_{1}}$ is the time-averaged velocity at the bottom of the flow, and $\sigma_{1}$ is its mean square error
Dou [40] considered a pulsating water flow but did not consider the impact of particle size and position on the incipient velocity and divided the particle starting probability criteria into weak movements, moderate movements, and general movements. The corresponding starting probabilities are, respectively, weak movement, $\varepsilon_{1}=0.0014$; middle movement, $\varepsilon_{2}=0.0228$; general movement, $\varepsilon_{3}=0.01585$. In this paper, the starting probability corresponding to the general motion is used as the starting probability of cement particles to obtain

$$
1-\Phi\left(\frac{u_{0}-\overline{u_{1}}}{\overline{\sigma_{1}}}\right)=0.01585
$$

From the numerical table of the normal distribution function (Table 1),

$$
\frac{u_{0}-\overline{u_{1}}}{\overline{\sigma_{1}}}=1
$$

Substituting equation (10) into equation (12), 


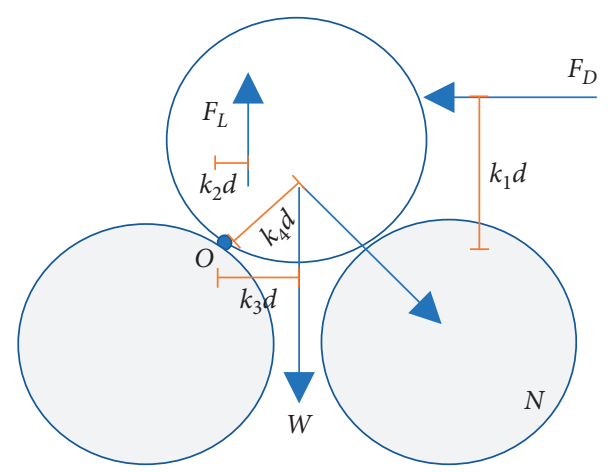

Figure 2: Stress analysis of cement particles.

TABLE 1: Numerical table of normal distribution function.

\begin{tabular}{lccccc}
\hline$x$ & 1.7 & 1.8 & 1.9 & 2.0 & 2.1 \\
\hline$\Phi(x)$ & 0.9554 & 0.9641 & 0.9713 & 0.9772 & 0.9821 \\
\hline
\end{tabular}

$$
\begin{aligned}
\overline{u_{1}}=\frac{u_{0}}{1.37} & =0.730 u_{0}, \\
\varepsilon & =0.01585
\end{aligned}
$$

By substituting equation (7) into equation (13) and after considering the starting probability, the near-bottom starting flow rate is

$$
\overline{u_{1}}=0.730\left[\frac{1}{\rho\left(C_{L}+C_{D}\right)}\right]^{1 / 2}\left[\frac{4\left(\rho_{p}-\rho_{g}\right) g}{3}+\frac{2 \sqrt{3} q_{0} \delta_{0}^{3}\left(\left(1 / t^{2}\right)-\left(1 / \delta_{1}^{2}\right)\right)\left(3-\left(t / \delta_{1}\right)\right)}{d}\right]^{1 / 2} .
$$

Because the near-bottom velocity is difficult to determine, it is replaced by the average vertical velocity $\overline{u_{2}}$.

The particle velocities follow an exponential distribution:

$$
u=u_{m}\left(1-\frac{y}{h}\right)^{m}
$$

where $u_{m}$ is the water hydrodynamic velocity at $y=h / 2$. Here, $h$ is the fracture aperture, and $u$ is the hydrodynamic velocity at distance $y$ from the bottom of the channel. The average vertical velocity is expressed as

$$
\overline{u_{2}}=\frac{u_{m}}{h} \int_{0}^{h}\left(1-\frac{y}{h}\right)^{m} \mathrm{~d} y=\frac{u_{m}}{1+m},
$$

and the near-bottom velocity

$$
\overline{u_{1}}=u_{m}\left(1-\frac{\mathrm{d}_{p}}{h}\right)^{m}
$$

Substituting equation (17) in equation (16), we obtain

$$
\overline{u_{2}}=\frac{1}{(1+m)}\left(1-\frac{\mathrm{d}_{P}}{h}\right)^{-m} \overline{u_{1}} \text {. }
$$

Substituting equation (14) in equation (18), we obtain

$$
\overline{u_{2}}=\frac{1}{(1+m)}\left(1-\frac{\mathrm{d}_{P}}{h}\right)^{-m}\left[\frac{1}{\rho\left(C_{L}+C_{D}\right)}\right]^{1 / 2}\left[\frac{4 \mathrm{~d}_{p}\left(\rho_{p}-\rho_{g}\right) g}{3}+\frac{2 \sqrt{3} \pi q_{0} \delta_{0}^{3}\left(\left(1 / t^{2}\right)-\left(1 / \delta_{1}^{2}\right)\right)\left(3-\left(t / \delta_{1}\right)\right)}{\pi d_{P}}\right]^{1 / 2}
$$

2.1.3. Optimal Plugging Flow Rate. Cement particles usually start to move in groups. To explain this phenomenon, the particle size is corrected, and the incipient velocity of a single particle becomes the incipient velocity of a particle group with diameter

$$
D=d+f(d) .
$$

In this expression, $d$ is the characteristic size of the cement particles, and $f(d)$ increases the particle size by an amount $f(d)=a d n^{x}$ [41], where $a$ is the proportionality relation between the additional and characteristic particle 
sizes. The number of internal particles per unit volume $n$ is related to the concentration of the cement slurry, and the exponent $x$ relates the additional particle size to the number of particles (here, we set $a=0.006$ and $x=0.335$ ).
Further, substituting equation (20) in equation (19), the optimal plugging flow rate is expressed as

$$
\overline{u_{3}}=\frac{1}{(1+m)}\left(1-\frac{D}{h}\right)^{-m}\left[\frac{1}{\rho\left(C_{L}+C_{D}\right)}\right]^{1 / 2}\left[\frac{4 D\left(\rho_{p}-\rho_{g}\right) g}{3}+\frac{2 \sqrt{3} \pi q_{0} \delta_{0}^{3}\left(\left(1 / t^{2}\right)-\left(1 / \delta_{1}^{2}\right)\right)\left(3-t / \delta_{1}\right)}{\pi D}\right]^{1 / 2} .
$$

\subsection{Test of the Plugging Law of Cement Slurry at High Hydraulic Gradient}

2.2.1. Test System. Herein, the plugging law of cement slurry is investigated under large-flow and high-hydraulic-gradient conditions. Experiments are performed in a self-developed adjustable dynamic water grouting test system. The plugging effect is observed at different water-cement ratios, grouting pressures, pipeline diameters, and other factors, thus providing theoretical support for grouting treatments of water inrush disasters. The test system is divided into five parts: a pipeline fracture simulation system, grouting control system, dynamic water simulation system, data acquisition system, and test monitoring system (Figure 3).

The pipeline fracture simulation system comprises two main parts: a plexiglass pipeline and pipeline bracket (Figure 4). The plexiglass pipe is composed of poly(methyl methacrylate), a lightweight, easily processed material with high transparency and mechanical strength. To ensure visibility, single pipes are connected through plexiglass flanges. The entire pipeline is placed on the pipeline bracket located $16 \mathrm{~cm}$ from the desktop. The grouting speed and flow are controlled using a modified hand-operated grouting pump, which is particularly suitable for small pressure control.

During the test, the hydrodynamic velocity is adjusted through the combined actions of the water pump, ball valve, and electromagnetic flowmeter. The electromagnetic flowmeter and pressure transmitter monitored the flow rate and pressure change of the water, respectively, flowing through the pipeline in real time and imported the results to a paperless recorder. The recording interval is one second. Table 2 presents the data acquisition parameters.

\subsubsection{Test Scheme}

(1) Orthogonal Test Scheme. The main test parameters are the pipeline diameter, hydrodynamic velocity, grouting pressure, and single-liquid water-cement ratio. The grout plugging effect against rock mass fractures is assessed based on the slurry deposition thickness and reverse diffusion distance. The experimental scheme (Table 3) is designed using orthogonal experimental theory.

(2) Test Scheme for Optimizing the Blocking Flow Rate. The test variables are the pipeline diameter, water-cement ratio, and hydrodynamic velocity. The water-cement ratio is varied at $0.8: 1,1: 1$, and $1.5: 1$, which are typical ratios in grouting engineering. The pipeline diameter is varied at 50 and $70 \mathrm{~mm}$. The hydrodynamic velocity is initially set to $0.1 \mathrm{~m} \cdot \mathrm{s}^{-1}$ and increased to $0.55 \mathrm{~m} \cdot \mathrm{s}^{-1}$ at $0.05 \mathrm{~m} \cdot \mathrm{s}^{-1}$ intervals. The grouting pressure is fixed. At the optimal plugging flow rate, the complete dispersion of the slurry in the pipeline is expected. In total, this comprehensive test method covers 54 test sets.

\section{Results and Discussion}

\subsection{Orthogonal Test Analysis}

3.1.1. Analysis of Slurry Deposition Thickness. The slurry deposition thickness is the most intuitive manifestation of the grouting effect in blocking rock mass fractures. Once the cement slurry is injected into the cracks of the rock mass, the strong bonding forces between the particles resist erosion owing to dynamic water. As the slurry continues to sediment and consolidate, the cross section of the water decreases, and the water flow is eventually blocked. The thickness of the slurry deposition depends on the pipeline diameter, hydrodynamic velocity, slurry water-cement ratio, grouting pressure, and other factors. Figure 5 shows the measured thicknesses of the slurry deposition.

The data are analyzed using an intuitive analysis method that reveals the primary and secondary relations between the various factors and slurry deposition thickness. The analysis steps are as follows:

(1) Add the test results under the conditions of various factors, and define them as $K i$

(2) Take an average of $K i$, and define it as $k i$

(3) Calculate the range (the difference between the maximum and minimum values)

Tables 4 and 5 present the results of the 70 and $50 \mathrm{~mm}$ diameter pipes, respectively.

In the pipes of both diameters, the most important parameter is the hydrodynamic velocity, followed by the water-cement ratio and grouting pressure. Figure 6 shows the influence of various factors on the retained slurry thickness.

Each factor analyzed in Figure 6 is obviously correlated with the retained slurry thickness. The trends are detailed below:

(1) In the $50 \mathrm{~mm}$ diameter pipe, the average deposition thickness decreases by $25 \%$ when the hydrodynamic 


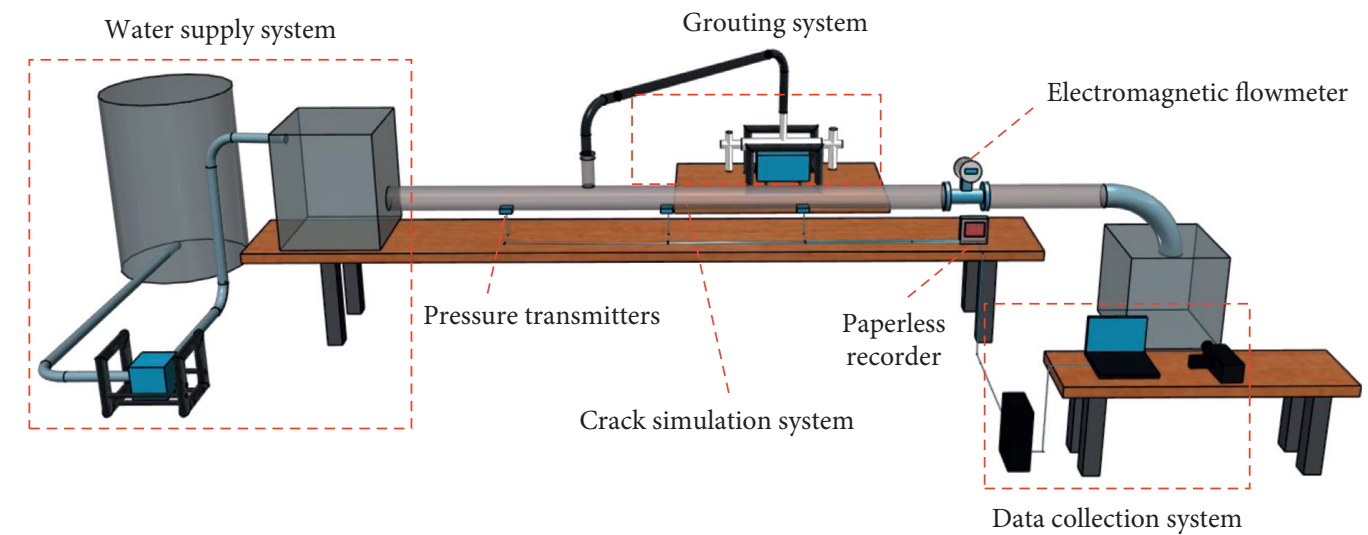

FIgURE 3: Self-developed test system of grouting plugs.

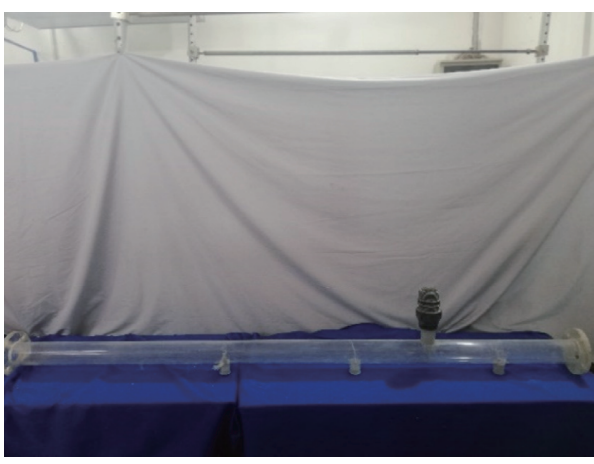

(a)

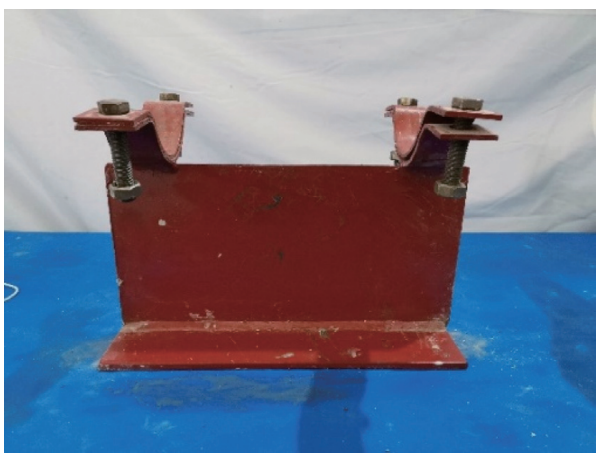

(b)

FIGURE 4: Simulation system for investigating pipeline fractures. (a) Organic glass pipeline. (b) Pipe bracket.

TABLE 2: Parameters of the pressure sensor and electromagnetic flowmeter.

\begin{tabular}{lccc}
\hline Types & Pressure sensor & Electromagnetic flowmeter & Paperless recorder \\
\hline Product number & PCM350 & MIK-R 9600 & OHR-F804 \\
Power supply & 24 VDC & 220 VDC & 220 VDC \\
Output signal & $4-20 \mathrm{~mA}$ & $4-20 \mathrm{~mA}$ & - \\
Measuring medium & Liquid & Water, oil, slurry & - \\
Precision & $0.5 \% \mathrm{FS}$ & $1.0 \%$ & $0.5 \%$ \\
\hline
\end{tabular}

TABLe 3: Scheme for determining the optimal plugging flow rate.

\begin{tabular}{lccc}
\hline Test number & Water-cement ratio & Injection pressure $(\mathrm{MPa})$ & ${\text { Hydrodynamic velocity }\left(\mathrm{m} \cdot \mathrm{s}^{-1}\right)}$ \\
\hline $1-1 \mathrm{a} / \mathrm{b}$ & $0.8: 1$ & 0.1 & 0.15 \\
$1-2 \mathrm{a} / 2 \mathrm{~b}$ & $0.8: 1$ & 0.2 & 0.35 \\
$1-3 \mathrm{a} / 3 \mathrm{~b}$ & $0.8: 1$ & 0.3 & 0.25 \\
$1-4 \mathrm{a} / 4 \mathrm{~b}$ & $1: 1$ & 0.2 & 0.25 \\
$1-5 \mathrm{a} / 5 \mathrm{~b}$ & $1: 1$ & 0.3 & 0.15 \\
$1-6 \mathrm{a} / 6 \mathrm{~b}$ & $1: 1$ & 0.1 & 0.35 \\
$1-7 \mathrm{a} / 7 \mathrm{~b}$ & $1.5: 1$ & 0.3 & 0.35 \\
$1-8 \mathrm{a} / 8 \mathrm{~b}$ & $1.5: 1$ & 0.1 & 0.25 \\
$1-9 \mathrm{a} / 9 \mathrm{~b}$ & $1.5: 1$ & 0.2 & 0.15 \\
\hline
\end{tabular}

velocity is increased from 0.15 to $0.25 \mathrm{~m} \cdot \mathrm{s}^{-1}$. The average deposition thickness further decreases by $11 \%$ when hydrodynamic velocity is increased from
0.25 to $0.35 \mathrm{~m} \cdot \mathrm{s}^{-1}$. In the $70 \mathrm{~mm}$ diameter pipe, the sedimentation thickness decreased by $17 \%$ when the hydrodynamic velocity is increased from 0.15 to 


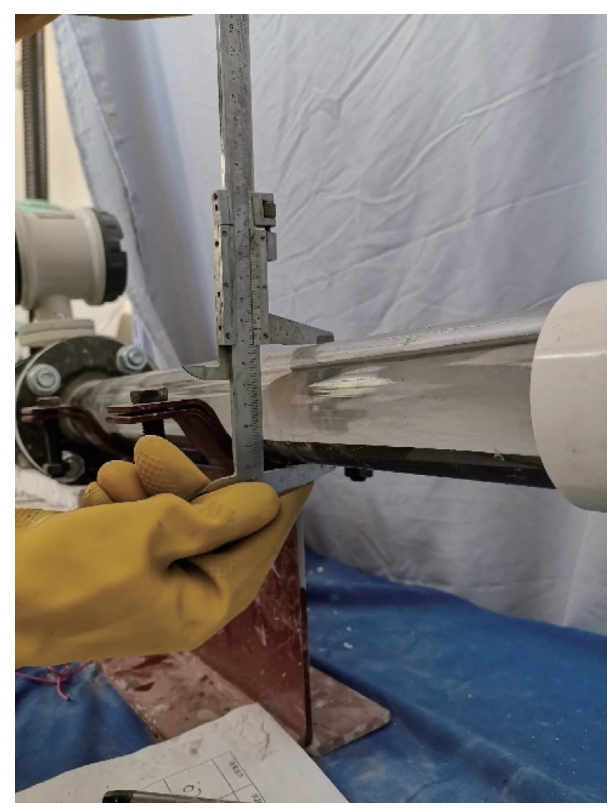

FIgURE 5: Thickness of the slurry deposition in pipes.

TABLE 4: Analysis of the slurry deposition thickness in the $70 \mathrm{~mm}$ diameter pipe.

\begin{tabular}{lccc}
\hline Factor & Water-cement ratio $(\mathrm{W} / \mathrm{C})$ & Hydrodynamic velocity $\left(\mathrm{m} \cdot \mathrm{s}^{-1}\right)$ & Injection pressure $(\mathrm{MPa})$ \\
\hline$K_{1}$ & 62 & 64 & 52 \\
$K_{2}$ & 53 & 53 & 54 \\
$K_{3}$ & 47 & 45 & 56 \\
$k_{1}$ & 20.7 & 21.3 & 17.3 \\
$k_{2}$ & 17.7 & 17.7 & 18 \\
$k_{3}$ & 15.7 & 6.3 & 18.7 \\
Range & 5 & Hydrodynamic velocity $>$ water-cement ratio $>$ injection pressure \\
Primary and secondary factor & \multicolumn{2}{c}{}
\end{tabular}

TABLE 5: Analysis of the slurry deposition thickness in the $50 \mathrm{~mm}$ diameter pipe.

\begin{tabular}{lccc}
\hline Factor & Water-cement ratio $(\mathrm{W} / \mathrm{C})$ & Hydrodynamic velocity $\left(\mathrm{m} \cdot \mathrm{s}^{-1}\right)$ & Injection $\mathrm{pressure}(\mathrm{MPa})$ \\
\hline$K_{1}$ & 70 & 77 & 59 \\
$K_{2}$ & 56 & 56 & 61 \\
$K_{3}$ & 54 & 50 & 63 \\
$k_{1}$ & 23.3 & 25.3 & 19.7 \\
$k_{2}$ & 18.7 & 18.3 & 20.3 \\
$k_{3}$ & 18 & 16.3 & 21 \\
Range & $5.3 \quad$ Hydrodynamic velocity $>$ water-cement ratio $>$ injection pressure \\
Primary and secondary factor & \multicolumn{2}{c}{1.3} \\
\hline
\end{tabular}

$0.25 \mathrm{~m} \cdot \mathrm{s}^{-1}$. It further decreased by $15 \%$ when the hydrodynamic velocity is increased from 0.25 to $0.35 \mathrm{~m} \cdot \mathrm{s}^{-1}$. The slurry deposition thickness is significantly negatively correlated with the hydrodynamic velocity.

(2) The thickness of the slurry deposition also decreases with an increase in the water-cement ratio. Increasing the water-cement ratio reduces the concentration of the solid phase; consequently, the plastic viscosity and ultimate shear force of the slurry decrease, thus significantly reducing the contact force between the slurry and pipeline and enhancing the scouring effect of the moving water.

(3) Under the same hydrodynamic velocity, reducing the pipe diameter increases the slurry deposition thickness, and the pipe is easily blocked. Conversely, in the $70 \mathrm{~mm}$ diameter pipe, a large surface area of the deposited slurry is washed by the dynamic water flow, intensifying the turbulent state of the dynamic water and inhibiting the deposition and aggregation of cement particles. 


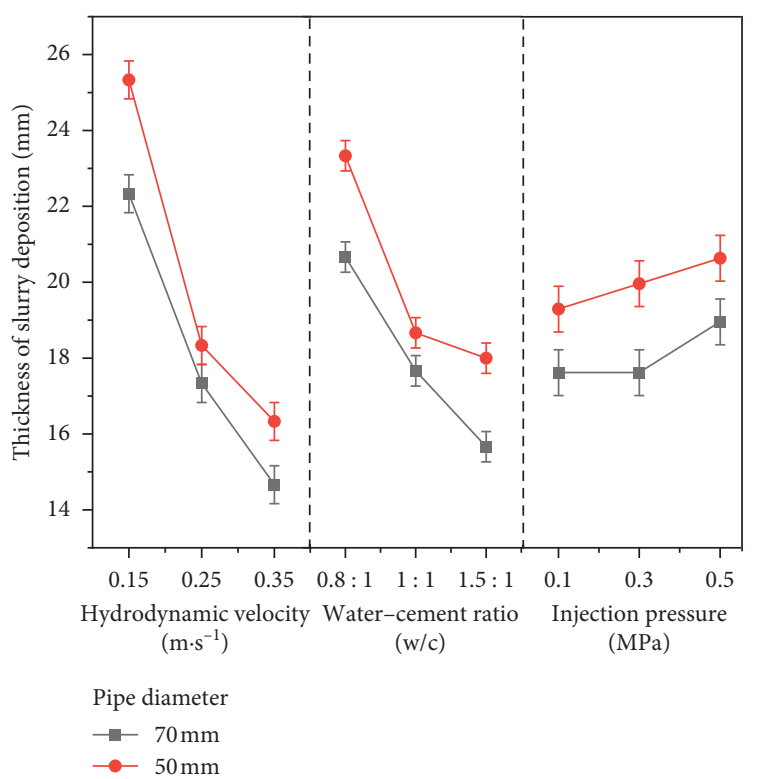

FIGURE 6: Influences of various factors on the proportion of the retained slurry thickness.

(4) Although increasing the grouting pressure increases the grout deposition thickness, the extremum of the grouting pressure is considerably smaller than those of the other factors (Tables 3 and 4), implying that the grouting pressure exerts a weak effect on the thickness of slurry deposition.

3.1.2. Analysis of the Reverse Diffusion Distance. The reverse diffusion distance of the grout largely affects the effectiveness of grouting in rock mass fractures and reflects the antiscouring ability of the grout. Figure 7 shows the reverse diffusion distances of the slurry measured through the pipes. Both ends of the ruler are fixed.

The influences of the above factors on the backwater diffusion distance are determined using the range analysis method, and the results are shown in Tables 6 and 7 .

Based on Tables 5 and 6, in the pipes of both diameters, the reverse diffusion distance is most strongly influenced by the hydrodynamic velocity, followed by the water-cement ratio, and then by the grouting pressure. Figure 8 shows the influence of various factors on the reverse diffusion distance.

The trends of the influencing factors on the reverse diffusion distance of the slurry are described as follows:

(1) The reverse diffusion distance of the slurry is negatively related to the hydrodynamic velocity of the water. This result is expected because flowing water counteracts the reverse diffusion. As the water flow rate increases, the resistance of the slurry increases; thus, the reverse diffusion distance decreases.

(2) The grouting pressure is positively correlated with the reverse diffusion distance of the slurry. The kinetic energy of the slurry in the pipeline is provided by the grouting pressure. When the grouting pressure is increased, the kinetic energy of the slurry

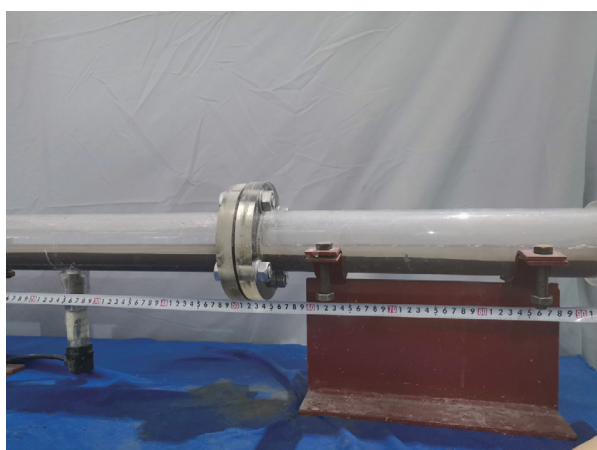

Figure 7: Backward diffusion distances of the slurry in the pipelines.

increases accordingly, enhancing the resistance to water flow and increasing the reverse diffusion distance of the slurry.

(3) The maximum reverse diffusion distance of the slurry is obtained at a water-cement ratio of $1: 1$. When the water-cement ratio is changed to $0.8: 1$, the solid-phase concentration of the slurry is increased, and the friction between the slurry and pipe wall becomes large. The strong antierosion ability increases the reverse diffusion distance of the slurry. When the water-cement ratio is $1.5: 1$, the spreading and dispersing ability of the slurry is weakened; hence, the cement particles are insufficiently agglomerated and passively washed away by water. Consequently, the reverse diffusion distance of the slurry decreases.

\subsection{Experimental Analysis and Theoretical Model Verification of Optimal Plugging Flow Rate}

3.2.1. Analysis of Optimal Plugging Flow Rate. In the orthogonal test, the hydrodynamic velocity of the water has the highest impact on the cement slurry deposition thickness. The greater the hydrodynamic velocity, the smaller the slurry deposition thickness. At some threshold of the hydrodynamic velocity, the cement slurry cannot deposit on the bottom of the fracture. This threshold flow rate is the optimal plugging flow rate. When the fluid velocity in the fracture exceeds the optimal plugging velocity, the grouting process is useless. Figure 9 shows the test results.

As observed in Figure 10, when the hydrodynamic velocity is small, the slurry deposition thickness is more affected by the water-cement ratio compared with the case when the hydrodynamic velocity is large. Increasing the hydrodynamic velocity reduces the influence of the watercement ratio on the slurry deposition thickness. At a hydrodynamic velocity of $0.2 \mathrm{~m} \cdot \mathrm{s}^{-1}$, the slurry deposition thickness differs by 6 and $9 \mathrm{~mm}$ between the water-cement ratios of 0.8 and 1.0, and 1.0 and 1.5 , respectively. When the hydrodynamic velocity is increased to $0.3 \mathrm{~m} \cdot \mathrm{s}^{-1}$, these differences decrease to 4 and $6 \mathrm{~mm}$, respectively, and when the hydrodynamic velocity is further increased to $0.4 \mathrm{~m} \cdot \mathrm{s}^{-1}$, these differences reduce to 3 and $5 \mathrm{~mm}$, respectively. At low 
TABle 6: Reverse diffusion distances in the $70 \mathrm{~mm}$ diameter pipe.

\begin{tabular}{lccc}
\hline Factor & Water-cement ratio $(\mathrm{W} / \mathrm{C})$ & Hydrodynamic velocity $\left(\mathrm{m} \cdot \mathrm{s}^{-1}\right)$ & Injection pressure $(\mathrm{MPa})$ \\
\hline K1 & 1770 & 2470 & 1510 \\
$K 2$ & 1900 & 1500 & 1720 \\
$K 3$ & 1300 & 1030 & 1740 \\
$k 1$ & 590 & 813 & 503 \\
$k 2$ & 633 & 500 & 573 \\
$k 3$ & 433 & 343 & 580 \\
Range & $157 \quad$ Hydrodynamic velocity $>$ water-cement ratio $>$ injection pressure \\
Primary and secondary factor & \multicolumn{2}{c}{}
\end{tabular}

TAble 7: Reverse diffusion distances in the $50 \mathrm{~mm}$ diameter pipe.

\begin{tabular}{lccc}
\hline Factor & Water-cement ratio $(\mathrm{W} / \mathrm{C})$ & Hydrodynamic velocity $\left(\mathrm{m} \cdot \mathrm{s}^{-1}\right)$ & Injection pressure $(\mathrm{MPa})$ \\
\hline$K 1$ & 1270 & 1610 & 1080 \\
$K 2$ & 1580 & 1010 & 1130 \\
$K 3$ & 510 & 740 & 1150 \\
$k 1$ & 423 & 537 & 360 \\
$k 2$ & 527 & 337 & 377 \\
$k 3$ & 170 & 247 & 383 \\
Range & $253 \quad$ Hydrodynamic velocity $>$ water-cement ratio $>$ injection pressure \\
Primary and secondary factor & \multicolumn{2}{c}{2930} \\
\hline
\end{tabular}

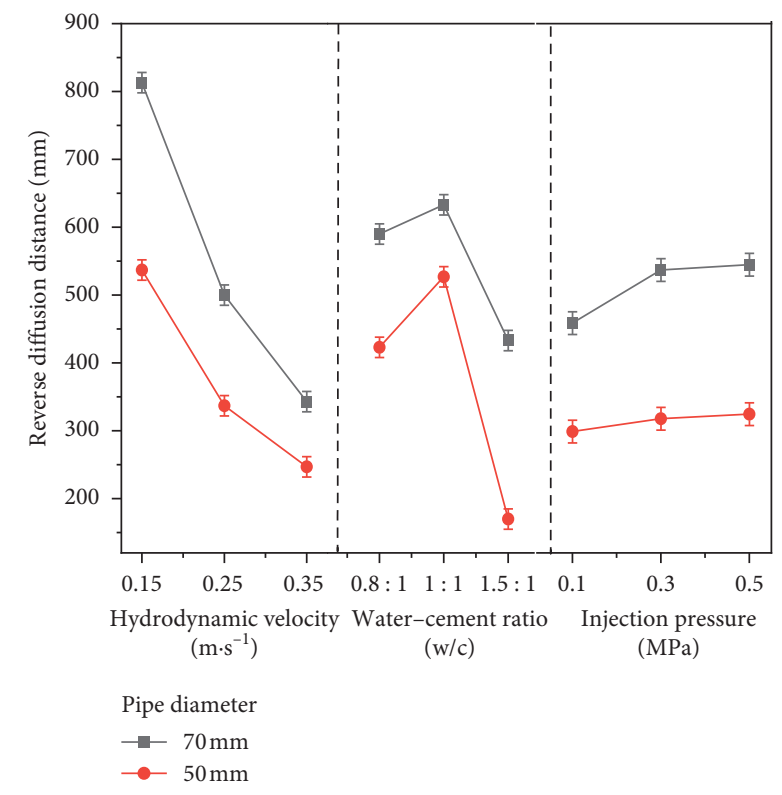

FIGURE 8: Influence of various factors on the reverse diffusion distance of the slurry.

flow rates, the scouring effect of water flow on the slurry is weak, and the slurry deposition thickness is mainly affected by the water-cement ratio. Increasing the dynamic water velocity increases the pulsation between the water molecules, and the main controlling factor becomes the hydrodynamic velocity, not the water-cement ratio. The impact of other factors on the slurry deposition thickness decreases. Based on the test results in the $50 \mathrm{~mm}$ diameter pipe, the optimal plugging flow rate (at which the slurry deposition thickness reduces to zero) is achieved at hydrodynamic velocities of $0.55,0.55$, and $0.50 \mathrm{~m} \cdot \mathrm{s}^{-1}$ with the slurries exhibiting watercement ratios of $0.8,1.0$, and 1.5 , respectively.
When the hydrodynamic velocity is low, increasing the pipe diameter reduces the thickness of the accumulation layer (Figure 7). However, when the flow rate approaches the optimal plugging flow rate, the accumulation layer thickness in the pipes of both diameters is more similar, indicating that as the water speed is increased, the slurry deposition thickness is less affected by the pipe diameter. At a watercement ratio of 1.0, the optimal plugging flow rates of the slurry in the 50 and $70 \mathrm{~mm}$ diameter pipes are 0.50 and $0.55 \mathrm{~m} \cdot \mathrm{s}^{-1}$, respectively.

In summary, the water-cement ratio and pipe diameter have little effect on the optimal plugging flow rate of the cement slurry. The optimal plugging flow rate ranges from 0.50 to $0.55 \mathrm{~m} \cdot \mathrm{s}^{-1}$ depending on the working conditions.

3.2.2. Comparison and Verification of Theoretical Models. The working conditions and material parameters of the test are provided as inputs to the optimal plugging flow rate model, and the results are compared with those of the indoor test for model validation. In the $50 \mathrm{~mm}$ diameter pipe, the optimal plugging flow rates at the water-cement ratios of 0.8 , 1.0 , and 1.5 are $0.55,0.55$, and $0.5 \mathrm{~m} \cdot \mathrm{s}^{-1}$, respectively, in the experiment, and $0.48,0.46$, and $0.44 \mathrm{~m} \cdot \mathrm{s}^{-1}$, respectively, in the model (Figure 11). The errors between the theoretical and experimental results are less than $0.1 \mathrm{~m} \cdot \mathrm{s}^{-1}$. The theoretical values tend to be smaller than the experimental results, and the error is reduced in pipes with a smaller diameter.

The error between the theoretical and experimental results is attributed to three causes: (1) the theory is based on certain assumptions that do not exactly reflect the actual situation, e.g., ignoring the lubrication effect of water on the particles and the influence of particle shape on the optimal plugging flow rate; (2) deviations inevitably arise from indoor test conditions, such as water pressure control, 


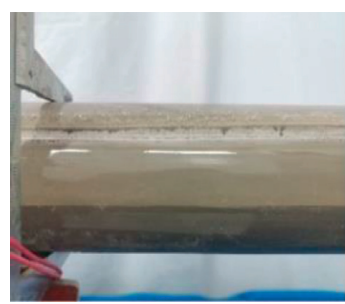

$0.2 \mathrm{~m} / \mathrm{s}$

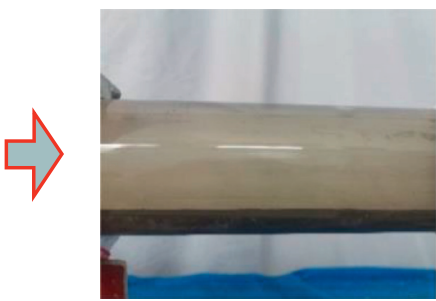

$0.35 \mathrm{~m} / \mathrm{s}$

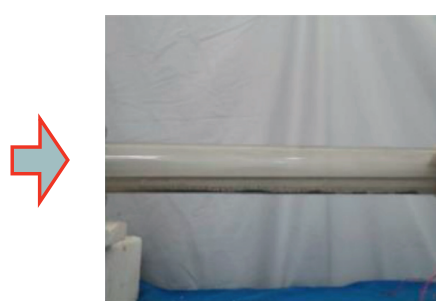

$0.54 \mathrm{~m} / \mathrm{s}$

FIgURE 9: Experimental results of the optimal blocking flow rate.

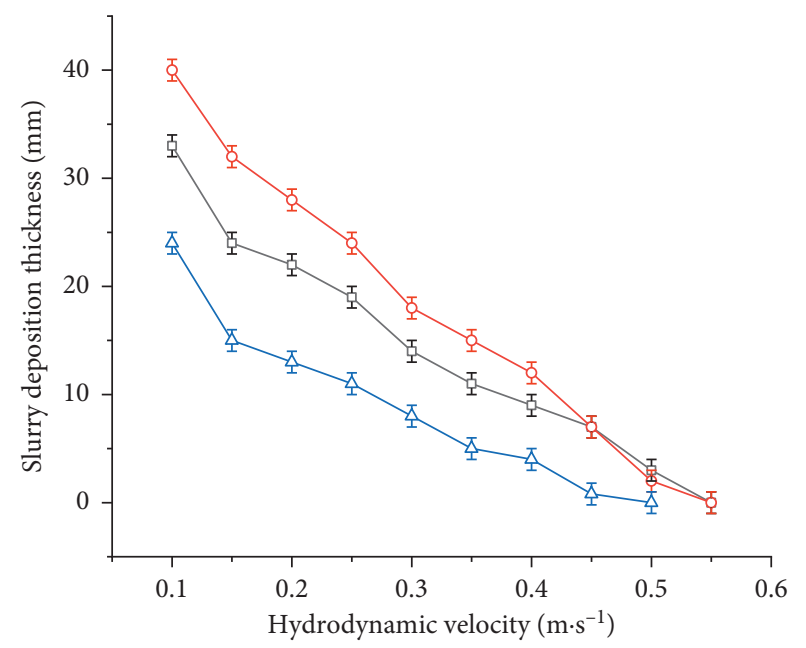

Water cement ratio

$\multimap 0.8$

$\rightarrow-1$

$\triangle-1.5$

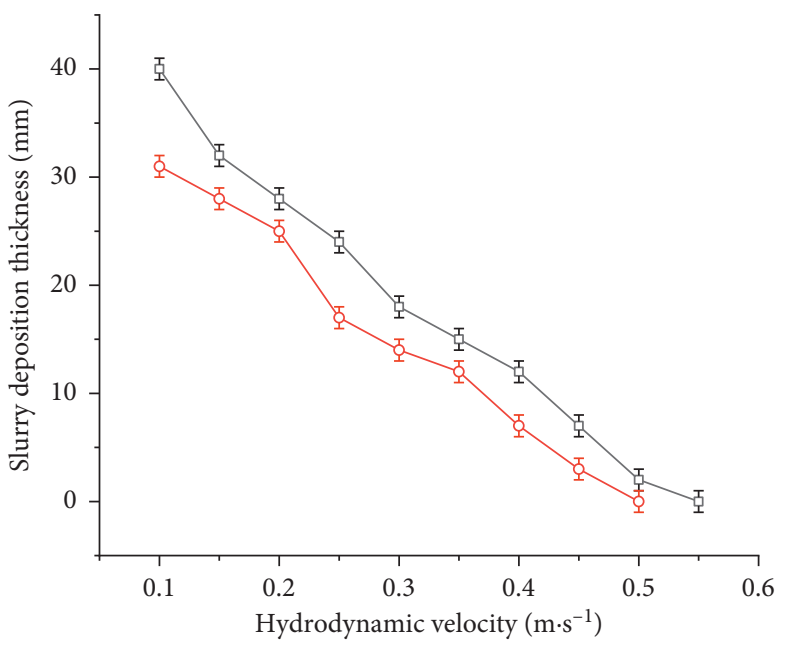

Pipeline diameter

$\rightarrow-50 \mathrm{~mm}$

$\multimap 70 \mathrm{~mm}$

(a)

(b)

Figure 10: Analysis of test results of the optimal blocking flow rate.

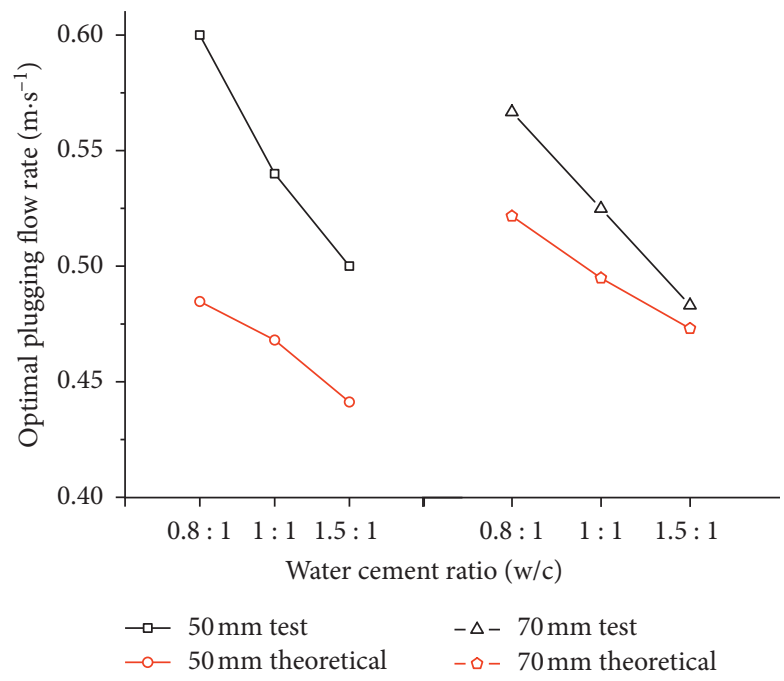

FIGURE 11: Results of the comparative analysis.

plexiglass tube roughness, and other factors; and (3) observation errors are introduced by the limitation of the sensor-discrimination ability and technical proficiency of the testers. However, the theoretical and experimental values are highly consistent, verifying the rationality of the optimal plugging flow rate model. 


\section{Conclusions}

The optimal plugging flow rate of the cement slurry is modeled using the particle motion-start theory, and the plugging law of the cement slurry at high flow rates is tested in a self-developed and adjustable dynamic water grouting test system. The theoretical model is verified by comparing the theoretical and experimental results. The findings of this study are summarized:

(1) In the optimal plugging flow rate model, the flow rate under which the cement particles started moving is defined as the optimal plugging flow rate. The proposed model provides theoretical guidance for cement slurry grouting and plugging under different conditions (fracture aperture and water-cement ratio) that affect the optimal plugging flow rate.

(2) An orthogonal test of the cement slurry deposition law is performed under a high hydrodynamic velocity. By selecting the slurry deposition thickness and reverse diffusion distance as evaluation indexes, the primary and secondary relations between the factors affecting each evaluation index are obtained in a range analysis.

(3) In an indoor test of the optimal plugging flow rate, the dependence of the slurry deposition thickness on the hydrodynamic velocity is determined in pipes with different diameters and for slurries with different water-cement ratios. When the hydrodynamic velocity is small, the slurry deposition thickness largely depends on the water-cement ratio and pipe diameter. When the flow rate of the dynamic water is increased, the influence of these factors on the slurry deposition thickness decreases.

(4) In the indoor test, the optimal plugging flow rate of the pure cement slurry under different working conditions is in the range of $0.50-0.55 \mathrm{~m} \cdot \mathrm{s}^{-1}$. The theoretical values agreed with the experimental values (with errors of $0.1 \mathrm{~m} \cdot \mathrm{s}^{-1}$ or less), thus verifying the rationality of the model.

\section{Data Availability}

The data used to support the findings of this study are available from the corresponding author upon request.

\section{Conflicts of Interest}

The authors declare that they have no commercial or associative interest that could represent any conflict of interest regarding the submitted work.

\section{Acknowledgments}

This study is funded by China Postdoctoral Science Foundation (grant no. 2017M623330XB), General Funding Project of Shanxi Natural Science Basic Research Program (grant no. 2018JM5126), Funding project of Xi'an University of Science and Technology, Xi'an Key Laboratory of
Geotechnical and Underground Engineering (grant nos. XKLGUEKF20-03)

\section{References}

[1] Q. Qian, "Challenges and countermeasures for the safety of geotechnical construction," Rock Mechanics and Rock Engineering, vol. 31, no. 10, pp. 1945-1956, 2012.

[2] J. Wu, S. C. Li, and Z. H. Xu, "Numerical analysis of gas-liquid two-phase flow after water inrush from the working face during tunnel excavation in a karst region," Bulletin of Engineering Geology and the Environment, vol. 78, no. 4, 2019.

[3] Z. H. Xu, X. Huang, S. C. Li, P. Lin, X. S. Shi, and J. Wu, "A new slice-based method for calculating the minimum safe thickness for a filled-type karst cave," Bulletin of Engineering Geology and the Environment, vol. 79, no. 2, 2020.

[4] J. Wu, S. C. Li, Z. H. Xu et al., "Flow characteristics and escape-route optimization after water inrush in a backwardexcavated karst tunnel," International Journal of Geomechanics, vol. 17, no. 4, 2017.

[5] Y. Kang, Q. Liu, H. Xi, and G. Gong, "Improved compound support system for coal mine tunnels in densely faulted zones: a case study of China's Huainan coal field," Engineering Geology, vol. 240, 2018.

[6] X. Wang, S. Li, Z. Xu, X. Li, P. Lin, and C. Lin, "An interval risk assessment method and management of water inflow and inrush in course of karst tunnel excavation," Tunnelling and Underground Space Technology incorporating Trenchless Technology Research, vol. 92, 2019.

[7] A. N. Beard, "Tunnel safety, risk assessment and decisionmaking," Tunnelling and Underground Space Technology incorporating Trenchless Technology Research, vol. 25, no. 1, 2009.

[8] L. Y. Wu, H. Bai, C. Yuan, G. Wu, C. Xu, and Y. Du, "A waterrock coupled model for fault water inrush: a case study in Xiaochang coal mine, China," Advances in Civil Engineering, vol. 2019, Article ID 9343917, 12 pages, 2019.

[9] H. Li, Y. Zhang, J. Wu, X. Zhang, L. Zhang, and Z. Li, "Grouting sealing mechanism of water gushing in karst pipelines and engineering application," Construction and Building Materials, vol. 254, Article ID 119250, 2020.

[10] S. Niu, Study on Grouting Technology of Cement Based Slurry under Large Flow and High Velocity Groundwater, China University of Mining and Technology, Xuzhou, China, 2016.

[11] S. Li, D. Pan, Z. Xu, P. Lin, and Y. Zhang, "Numerical simulation of dynamic water grouting using quick-setting slurry in rock fracture: the sequential diffusion and solidification (SDS) method," Computers and Geotechnics, vol. 122, Article ID 103497, 2020.

[12] B. Liu, J. Huang, Y. Jiang, J. Gao, Z. Zheng, and X. Jiang, "Simulation study on effective grouting performance of impact cement paste," Concrete, vol. 8, pp. 152-155, 2019.

[13] W. Cui, J. Huang, H. Song, and M. Xiao, "Development of two new anti-washout grouting materials using multi-way ANOVA in conjunction with grey relational analysis," Construction and Building Materials, vol. 156, pp. 184-198, 2017.

[14] G. Zhang, S. Hui, W. Li, and W. Sui, "Experimental investigation on pouring aggregate to plug horizontal tunnel with flow water," Water, vol. 12, no. 6, 2020.

[15] S. Li, X. Zhang, Q. Zhang et al., "Research on mechanism of grout diffusion of dynamic grouting and plugging method in water inrush of underground engineering," Rock Mechanics and Rock Engineering, vol. 30, no. 12, pp. 2377-2396, 2011. 
[16] T. Chang, Study on the Sealing Mode and Control Method of Multipipe Water Gushing Grouting Diffusion in Karst Area, Shandong University, Jinan, China, 2020.

[17] W. Zhang, C. Han, L. Zhang et al., "Grouting mechanism of cement-based slurry in a concentric annulus under high groundwater pressure," Advances in Civil Engineering, vol. 2019, Article ID 2587035, 15 pages, 2019.

[18] X. Du, H. Fang, S. Wang, B. Xue, and F. Wang, "Experimental and practical investigation of the sealing efficiency of cement grouting in tortuous fractures with flowing water," Tunnelling and Underground Space Technology, vol. 108, 2021.

[19] Y. Liang, W. Sui, and J. Qi, "Experimental investigation on chemical grouting of inclined fracture to control sand and water flow," Tunnelling and Underground Space Technology Incorporating Trenchless Technology Research, vol. 83, 2019.

[20] O. Saeidi, H. Stille, and S. R. Torabi, "Numerical and analytical analyses of the effects of different joint and grout properties on the rock mass groutability," Tunnelling and Underground Space Technology, vol. 38, pp. 11-25, 2013.

[21] P. Yang and X. Sun, "Single fracture grouting numerical simulation based on fracture roughness in hydrodynamic environment," Electronic Journal of Geotechnical Engineering, vol. 20, no. 1, pp. 59-67, 2015.

[22] R. Liu, L. Zhang, Q. Zhang et al., "Numerical simulation of crack grouting process of quick setting slurry with running water and its experimental verification," Rock Mechanics and Rock Engineering, vol. 36, no. S1, pp. 3297-3306, 2017.

[23] S. Mohajerani, A. Baghbanan, R. Bagherpour, and H. Hashemolhosseini, "Grout penetration in fractured rock mass using a new developed explicit algorithm," International Journal of Rock Mechanics and Mining Sciences, vol. 80, 2015.

[24] W. Wang and B. Hu, "A new technology of rapid sealing roadway in Luotuoshan coal mine," Procedia Earth and Planetary Science, vol. 3, pp. 429-434, 2011.

[25] Q. Zhang, J. Li, B. Liu, and X. Chen, "Directional drainage grouting technology of coal mine water damage treatment," Procedia Engineering, vol. 26, 2011.

[26] L. I. Cai-Hui, "Interception-plugging technology for supergiant water inrush laneway in mine," Journal of North China Institute of Science and Technology, vol. 6, no. 4, pp. 106-107, 2009.

[27] W. Zhang, S. Li, J. Wei et al., "Grouting rock fractures with cement and sodium silicate grout," Carbonates and Evaporites, vol. 33, no. 2, 2018.

[28] S. Li, Z. Sun, R. Liu et al., "Research on phase interface characteristics of cement-silicate grout based on crack grouting with dynamic water," Rock Mechanics and Rock Engineering, vol. 32, no. 8, pp. 1640-1646, 2013.

[29] W. Sui, J. Liu, W. Hu, J. Qi, and K. Zhan, "Experimental investigation on sealing efficiency of chemical grouting in rock fracture with flowing water," Tunnelling and Underground Space Technology, vol. 50, pp. 239-249, 2015.

[30] Z. Gailing, Z. Kaiyu, G. Yue, and W. Wenxue, "Comparative experimental investigation of chemical grouting into a fracture with flowing and static water," Mining Science and Technology, vol. 21, no. 2, 2011.

[31] H. Fu, P. An, K. Li, G. Cheng, J. Li, X. Yu et al., "Grouting design of rich water tunnels and the calculation of distance between annular blind pipes," Advances in Civil Engineering, vol. 2020, Article ID 8873971, 10 pages, 2020.

[32] R. Durand, The Hydraulic Transportation of Coal and Other Materials in Pipes, Colloquium of National Coal Board, London, UK, 1952.
[33] C. H. J. Bong, T. L. Lau, A. A. Ghani, and N. W. Chan, "Sediment deposit thickness and its effect on critical velocity for incipient motion," Water Science and Technology, vol. 74, no. 8, 2016.

[34] X. J. Fei, Hydraulics of Slurry and Granular Material Transport, Tsinghua University Press, Beijing, China, 1994.

[35] E. Rabinovich and H. Kalman, "Incipient motion of individual particles in horizontal particle-fluid systems: a. experimental analysis," Powder Technology, vol. 192, no. 3, pp. 318-325, 2009.

[36] A. Nasrollahi, A. A. Salehi Neyshabouri, G. Ahmadi, and M. Montazeri Namin, "Numerical simulation of incipient particle motion," International Journal of Sediment Research, vol. 35, no. 1, pp. 1-14, 2020.

[37] B. Li, F. Cozzoli, L. M. Soissons, T. J. Bouma, and L. Chen, "Effects of bioturbation on the erodibility of cohesive versus non-cohesive sediments along a current-velocity gradient: a case study on cockles," Journal of Experimental Marine Biology and Ecology, vol. 496, pp. 84-90, 2017.

[38] J. Schobesberger, P. Lichtneger, C. Hauer, H. Habersack, and C. Sindelar, "Three-dimensional coherent flow structures during incipient particle motion," Journal of Hydraulic Engineering, vol. 146, no. 5, 2020.

[39] R. J. Zhang, River Sediment Dynamics, China Water and Power Press, Beijing, China, 1998.

[40] G. Dou, "Re-discussion on the initial velocity of sediment," Journal of Sediment Research, vol. 6, pp. 1-9, 1999, in Chinese.

[41] C. Kuang, Y. H. Zeng, J. Gu, and D. Q. Ma, "Settling velocity of sediment particle clouds," Journal of Tongji University (Natural Science), vol. 44, no. 12, pp. 1845-1850, 2016. 